\title{
Las Unidades del Dolor en la era COVID-19
}

\author{
The Pain Units in the COVID-19 era
}

La Organización Mundial de la Salud (OMS) advirtió en septiembre de 2019 que "el mundo se estaba enfrentando a un número creciente de epidemias de enfermedades infecciosas" (1). Durante el siglo XXI estamos viviendo un aumento en la frecuencia de epidemias:

- 2002-2003: SARS (770 muertes).

- 2009-2010: gripe porcina [200.000 muertes].

- 2012-actualidad: MERS (850 muertes).

- 2014-2016: ébola [11.300 muertes].

- 2019-2020: COVID-19.

En la actualidad, a los 6 meses del primer contagio COVID-19 en China, el número de afectados por COVID-19 a nivel mundial supera los 7.000.000, el número total de muertes los 400.000, de ellas más de 27.000 en España, con un indicador de muertes por millón de habitantes en nuestro país de 580. La métrica utilizada para el seguimiento de la pandemia ha sido muy discutida; se han utilizado más los datos absolutos que las tasas y el número de fallecidos por habitante ha sido poco utilizado, cuando es el indicador más fiable entre los disponibles [2].

El hecho es que estamos viviendo un momento histórico. En los últimos cien años no había ocurrido algo así. Durante la crisis del COVID-19 hemos sentido miedo, rechazo social, muerte y enfermedad, pero también han destacado la abnegación, las curaciones, el apoyo social y el esfuerzo investigador. Luchamos contra una enfermedad infecciosa producida por un virus nuevo, fruto de una mutación reciente. Se trata de un virus de comportamiento sorprendente, con un peligroso carácter "silencioso" y de difícil diagnóstico, con inmunidad aún en estudio y sin tratamiento específico ni vacuna (en fase de investigación] [3]. Sin duda es un periodo excepcional para nuestra salud pública y nuestro sistema sanitario. Como profesionales de la salud hemos trabajado juntos en situaciones extremas, más cerca que nunca de las personas afectadas, de sus familias y de nuestros propios compañeros, en un escenario inédito lleno de angustia, miedo y pérdida. La situación que estamos viviendo aumenta la conciencia de la temporalidad de la especie humana y nos lleva a cuidar nuestro futuro.

A medida que la crisis actual vaya retrocediendo, debemos recordar las lecciones aprendidas. Llegará el momento de evaluar lo que ha funcionado, y lo que sí que debemos tener claro es que no podemos volver al status quo anterior.

Tenemos retos trascendentales; ahora en periodo denominado de desescalada no podemos hacer un reset. Tendremos que convivir con pacientes afectados por el virus, aprovechando experiencias aprendidas para innovar, incorporando nuevas herramientas y habilidades, superando conceptos anquilosados. Es el momento de más teleasistencia y coordinación, y de hospitales divididos en zonas COVID y no COVID.

Hay que poner las llamadas "tecnologías de la comunicación e información" (TIC) al servicio de procesos asistenciales efectivos para reservar la presencia física del enfermo a contactos insustituibles, sin perder la cercanía. Esto obliga a muchos profesionales a someterse a un proceso de aprendizaje para adaptarse, los contratos de gestión de los servicios deben valorar la efectividad de la visita virtual y la seguridad de los actos (en definitiva, de los resultados) por delante de la productividad.

En las unidades del dolor es el momento de replantear y reforzar la relación entre facultativos de diferentes especialidades, a nivel extrahospitalario y hospitalario (adaptación mutua], y los nuevos roles para enfermeras y administrativos en el proceso asistencial (4). Para ello, deberíamos buscar objetivos compartidos entre todos, lo que significa atenuar expectativas profesionales individuales y sustituirlas por colectivas. 
Volver a una "nueva normalidad" no será nada fácil. Se acompañará de "nuevas presiones", intuimos la presión de la ciudadanía y de la opinión pública que, en un entorno de empobrecimiento social (5), cuando se pierda el miedo a acercarse a nuestras consultas, se reclamarán soluciones urgentes ante el retraso de procedimientos, tratamientos o intervenciones que cada uno estuviera esperando y que tuvieron que paralizarse.

Desde el punto de vista social, el COVID-19 ha sido transversal, sin límites de edad, geográficos, raciales, de clase social, etc., y como resultado, los contagios y la demanda de atención generada ha sido muy elevada, desbordante. En este contexto, y concretamente para los profesionales implicados en el tratamiento del dolor, debemos preguntarnos ¿cómo priorizar una demanda que ahora más que nunca excede la capacidad de la oferta?, ¿cómo priorizar todas las pruebas y tratamientos que se han pospuesto debido a la pandemia?, ¿cómo organizar las listas de espera?, o ¿cómo conciliar los casos de COVID-19, que continuará habiendo, con los pacientes habituales? ¿Deberían definirse los criterios para las listas de espera, o sería mejor poner en cuestión las prácticas profesionales? De hecho, hemos constatado que algunos tratamientos eran menos necesarios de lo que pensábamos.

La crisis también ha puesto en valor la misión de los hospitales [6]. En el caso del tratamiento del dolor debemos ir más allá: esta misión debe extenderse a la comunidad. Los cuidados se deben prestar en una red de atención integrada que incluye a médicos de familia y estructuras intermedias (atención domiciliaria, lugares para personas vulnerables, etc.].

Por otro lado, la adopción de innovaciones (organizativas o tecnológicas) y diversas formas de cooperación se ha hecho sin vacilar, incluso en aquellos casos en los que no habían sido aceptadas previamente o que requerian procedimientos largos y complejos. Este ha sido el caso de la telemedicina, que nos ha permitido un seguimiento y atención de personas desde su domicilio o en dispositivos extrahospitalarios.

No obstante, la salud digital (e-health), aunque está en la agenda de los gobiernos, su desarrollo es todavía limitado y desigual. La tecnología existe, pero aún falta la definición y el desarrollo de un modelo organizativo y asistencial (cartera de servicios, proceso, protocolos de triaje y atención, recogida y análisis de datos].

La pandemia nos ha enseñado que debemos incorporar plenamente la telemedicina y el uso de aplicaciones en nuestras unidades del dolor. Para ello se necesita adaptar el marco jurídico, la regulación y los modelos de financiación que permitan una utilización efectiva de las TIC y que tengan en cuenta las implicaciones, particularmente en términos de seguridad y protección de datos.

Es necesario combinar el conocimiento tradicional de la investigación médica con el de big data y la inteligencia artificial, respetando las cuestiones éticas, de derecho y privacidad.

Debemos plantearnos también el efecto económico y financiero de la pandemia, que con toda seguridad provocará una crisis de tesorería a corto/medio plazo. Puede darse incluso una triste paradoja: las organizaciones profesionales que han estado en la primera línea de atención, con exceso de trabajo y estrés significativo, pueden estar en riesgo económico después de la crisis. La salud debería convertirse en una inversión social, especialmente en países como el nuestro, donde la mortalidad ha sido muy elevada. Es necesario proporcionar un sistema de financiación excepcional.

¡Es la primera vez que el mundo entero se detiene! Ahora es el momento de avanzar de nuevo y orientarnos hacia el Value Based Healthcare [3].

No olvidemos que hace poco más de dos meses, de un día para otro, nuestros pacientes de las unidades del dolor se quedaron sin ningún tipo de atención presencial; nuestra respuesta fue rápida y dimos la importancia que se merece al acompañamiento desde la unidad, dando atención telefónica a todos los pacientes que tenían visita presencial programada; quizás es el momento de plantearnos si estábamos infrautilizando la visita no presencial en nuestras unidades. Ahora es el momento de sensibilizarnos sobre las posibilidades, ventajas y pertinencia de la telemedicina, de manera que sea una práctica comúnmente aceptada, remarcar la importancia de la comunicación entre especialistas que tratan el dolor y el descubrimiento de las webinars como herramienta de formación e intercambio científico.

En esta nueva fase del COVID debemos conciliar tres situaciones:

1. Persistirán los casos de COVID que requerirán un flujo separado y un manejo diferente en la fase aguda y en la fase de recuperación.

2. La necesidad de organizar la recuperación de la actividad en stand by, actividad que estaba planificada y que tuvo que ser cancelada, y la demanda que no se ha manifestado debido al COVID.

3. Normalizar la gestión de la actividad habitual. 
¡La coexistencia de estas tres situaciones será un reto! Organizar flujos diferenciados, mantener criterios de seguridad y aislamiento, etc., serán desafíos. Pero el reto principal será sobre todo establecer criterios de priorización y garantizar un uso eficiente de los recursos disponibles.

En este escenario que se nos plantea es de suma importación la implicación de las sociedades científicas, el poder disponer de información detallada, actualizada, consensuada y de protocolos de actuación en esta época COVID es fundamental. La publicación de recomendaciones asistenciales, como las del artículo que publica la Sociedad Española del Dolor en este número, es de gran ayuda en estos momentos en los que necesitamos unas directrices de actuación segura que permitan el mejor tratamiento del dolor; nuestros pacientes se lo merecen.

\section{A. Montero Matamala Jefe del Servicio de Anestesiología, Reanimación y Tratamiento del Dolor. Hospital Universitario Arnau de Vilanova de Lleida. Profesor Titular. Facultad de Medicina de la Universidad de Lleida. Coordinador del Grupo del Dolor Musculoesquelético de la SED}

Correspondencia: Antonio Montero Matamala amontero@comll.cat

\section{BIBLIOGRAFÍA}

1. OMS. Un Monde en Péril: Rapport annuel sur l'état de préparation mondial aux situations d'urgence sanitaire. Conseil mondial de suivi de la préparation [Internet]. 2019. Disponible en: https://reliefweb. int/sites/reliefweb.int/files/resources/GPMB_Annual_Report_-_Exec_Summary_Foreword_and_About_ GPMB_French.pdf

2. Worldometer [Internet]. Coronavirus Update 2020. Disponible en: https://www.worldometers.info/ coronavirus/.

3. Johns Hopkins University and Medicine. Coronavirus Ressource Center [Internet]. 2020. Disponible en: https://coronavirus.jhu.edu/.

4. Jackson D, Bradbury-Jones C, Baptiste D, Gelling L, Morin K, Neville S, et al. Life in the pandemic: Some reflections on nursing in the context of COVID-19. J Clin Nurs. 2020. DOI: 10.1111/jocn.15257.

5. The Global Risks Report 2016 [Internet]. World Economic Forum. Eleventh Edition, 2016. Disponible en: https://www.weforum.org/reports/the-global-risks-report-2016.

6. Barrubés J, Honrubia L, de Vicente M, Portella E, Día O, Barreteau A, et al. La pandemia del COVID-19. Implicaciones y reflexiones [Internet]. Antares Consulting. 2020. Disponible en: https://www.antaresconsulting.com/pdf/Antares\%20Consulting_InformeCOVID19_ES.pdf. 